\title{
OPŠTE KARAKTERISTIKE HIBERNOENGLESKOG
}

Varijetet engleskog koji se govori u Irskoj u novije vreme dobija naziv hibernoengleski (Hiberno-English). Iako se za ovaj varijetet često koristi i termin irski engleski (Irish English), kao i još neki srodni, npr. Anglo-Irish, za potrebe ovog teksta koristićemo naziv hibernoengleski, odnosno skraćenicu HE. Rad je pisan bez velikih naučnih pretenzija, odnosno s namerom da u kratkim i opštim crtama opiše ovaj varijetet i tako ga približi čitaocima koji su zainteresovani za varijetete engleskog jezika. Nažalost, zbog ograničenog prostora, ovde ne možemo dublje ući u karakteristike HE i svega onoga što je bitno za njegov detaljan opis.

\section{IS T OR I JA T}

Današnji irski varijetet (HE) nastao je iz interakcije irskog jezika, tadašnjeg engleskog i donekle od škotskih varijeteta engleskog jezika. Ipak, kako navode neki relevantni autori (Gramley \& Pätzold 2003: 240), za formiranje današnjeg HE najbitniji su govori koji potiču iz Engleske. Može se konstatovati da engleski dolazi u Irsku u XII veku. U tom periodu iz Engleske stižu normanski osvajači, koji donose francuski i engleski jezik, mada se francuski, kao nebitan, relativno kratko održao. Ipak, jači uticaj engleskog jezika osetiće se nekoliko vekova kasnije, odnosno u XVI i naročito XVII veku, kada veliki broj stanovnika Britanije pristiže u Irsku u sklopu politike Henrija VIII, koji je želeo da Irska potpuno potpadne pod englesku vlast. Glavna odlika ove politike sastojala se u oduzimanju zemlje Ircima i dodeljivanju poseda Englezima, koji su u Irskoj stvarali tzv. plantaže. Novi naseljenici, koji su uglavnom došli iz Škotske, potiskivali su domaće stanovništvo sa severa na jug. Iako je tada irski jezik i dalje bio široko rasprostranjen, bitna je činjenica da Irci praktično gube domaću elitu, a starom društvenom uređenju zadat je poslednji udarac (Hogan 1927/1970: 52). Iako irski počinje polako da opada, prema podacima koje navodi Filpula (Filppula 1999: 7), irski se obilato koristio za širenje protestantizma, a u XVIII veku njime se služilo oko dve trećine stanovništva, dok je pred kraj tog veka bar polovina stanovništva znala samo irski ili ga je najradije koristila u svakodnevnoj komunikaciji. Na istom mestu ovaj autor navodi druge izvore prema kojima je tek polovinom XVIII veka irski počeo da se sve manje koristi među domaćim stanovništvom. Otprilike na samom početku XIX veka, engleski počinje da jače potiskuje jezik domaćeg stanovništva, pa se ovaj period uzima kao ključni za nestanak irskog i razvoj HE. Ovo se može 
povezati i sa činjenicom da je Irska formalno postala deo Ujedinjenog Kraljevstva 1801. godine i engleski postaje institucionalizovan. Vlasti otvoreno nameću engleski i pokušavaju da iskorene irski, a decu u školama čak i kažnjavaju ukoliko progovore na svom maternjem jeziku. Već sredinom veka engleski je postao toliko dominantan da je domaće stanovništvo i kod kuće izbegavalo da govori irski. Iako je danas to prvi zvanični jezik Republike Irske, veoma mali broj Iraca ga koristi kao prvi jezik.

Kao što je slučaj i sa mnogim drugim jezicima, za HE ne može se reći da je homogen, ali postoje neke opšte karakteristike koje će biti navedene u daljem tekstu.

\section{I ZGOVOR}

Za poređenje izgovora HE koristićemo RP (Received Pronunciation), standardni opšteprihvaćeni izgovor engleskog jezika.

U sledećoj tebeli date su najopštije i najčešće razlike.

\begin{tabular}{|l|l|l|l|}
\hline HE & RP & PRIMER & NAPOMENA \\
\hline $\mathrm{e}:$ & i: & key & \\
\hline əI & गI & join & najčešće na jugu \\
\hline O: & əU & boat & \\
\hline गI, əI & aI & night & \\
\hline $\mathrm{t}$ & $\theta^{1}$ & thin & v. fusnotu \\
\hline $\mathrm{d}$ & ठ & this & u nekim dijalektima /ð/ se očuvalo \\
\hline$[1]$ & {$\left[{ }^{1}\right]$} & elephant & nije nikada velarizovano u HE \\
\hline $\int$ & s & stop & obično ispred $/ \mathrm{t}, \mathrm{n}, \mathrm{l} /$ \\
\hline
\end{tabular}

Od ostalih karakteristika možemo izdvojiti i sledeće:

- / $/$ se izgovara umesto $/ \Lambda /$ u rečima kao što su but ili cut;

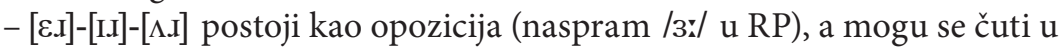
rečima koje tu nekadašnju razliku reflektuju u pravopisu, kao npr. herd, bird, curd;

- / $\Lambda$ J i / /EI/ uz izvesne varijacije mogu se čuti u govoru Dablina;

- /e/ se skoro izjednačilo sa /I/ u govoru Korka i okoline, najčešće ispred nazala;

- /o:. / i /D./ se razlikuju u rečima kao što su hoarse i horse;

- /r/ se uvek izgovara, bez obzira na poziciju, što nije slučaj sa RP;

- /w/ i / $/ \mathrm{M} /$ se razlikuju u rečima kao što su wine i whine;

- /k/ i /g/ imaju različite alofone u odnosu na RP, pa se u rečima kao npr. car ili garden izgovaraju sa $\left[\mathrm{k}^{\mathrm{j}}\right]$ odnosno $\left[\mathrm{g}^{\mathrm{j}}\right]$, što je uslovljeno vokalom koji im sledi;

- /t/ se uglavnom izgovara kao frikativ ukoliko se nađe uz $/ \mathrm{s} / \mathrm{i} / \mathrm{J} /$, ako je pred vokalom ili na kraju reči; u nekim dijalektima se spoj /tj/ izgovara kao /k/, tako da se fortune izgovara kao /'fprku:n/ 
- /h/ se ponekad izgovara na kraju reči koje se završavaju nekim konsonantima, kao npr. u McGrath/mə'gıæh/;

- /w/ se često realizuje kao zvučni bilabijalni frikativ [ $[\beta]$;

- epenteza postoji u rečima kao što su film ['filəm] ili forum ['fə.əm], tj. kada se neki konsonant nađe ispred $/ \mathrm{m} /$.

Jednu od takođe bitnih razlika na fonološkom nivou predstavlja akcentovanje. Kao jednu od najbitnijih osobina Kristal (Crystal 2003: 337) navodi pomeranje akcenta, pri čemu primarni dolazi kasnije nego u RP, a kao ilustrativne primere navodi triangle, safeguard i diagnose. Na istom mestu ovaj autor navodi i da se akcenat pomera kod glagolskih sufiksa u rečima sa tri i više sloga, kao educate, advertise ili prosecute, kao i u oblicima educating ili complicated, koji sadrže flektivne sufikse. Kristal spominje i višesložne imenice u kojima slog kome sledi više konsonanata teži da privuče akcenat, a kao primere navodimo orchestra, discipline i character.

\section{G R A M A T I K A}

Kako navodi Filpula (Filppula 1999: 13), u izgovoru i vokabularu (što naročito važi za jug), vidljivi su uticaji irskog jezika, kao i starijih varijeteta engleskog. Međutim, kada govorimo o gramatici, sintaksi i idiomu, najjači je uticaj irskog, iako je taj jezik ograničen na veoma mali broj izvornih govornika. Neki autori osporavaju ovu tvrdnju, pa se često može naći i načelna podrška popularnom tumačenju da je HE mešavina šekspirovskog engleskog i irskog jezika kakvim je govorilo domaće plemstvo. Haris (Harris 1993: 140) pak smatra da su za razvoj HE bitniji rani savremeni engleski (Early Modern English) i varijeteti engleskog koji su se govorili u Škotskoj. Bilo kako bilo, usled nedostatka dovoljno preciznih podataka iz tog doba teško je dati konačan sud o najbitnijem uticaju, ali je neosporno da je keltski element odigrao veoma bitnu ulogu.

Pri analizi morfoloških osobenosti HE navešćemo samo najkarakterističnije crte, jer bi iscrpniji prikaz zahtevao i opis više dijalekata. Primere koje ćemo navesti preuzeti su uglavnom od Filpule i sa više irskih foruma na internetu, a rečenice u kojima su dati po potrebi su skraćivane.

Ukoliko počnemo od kategorije množine, lako se može primetiti da se glagolski oblik jednine često slaže sa imenicama u množini, i to najčešće onim koje označavaju količinu. Rečenica $A$ hundred mile is as much as I ever went round from where I am sasvim je prihvatljiva za govornika HE. Osim toga, lična zamenica you ima oblik yous/youse ukoliko govornik govori o više osoba. Brojive imenice upotrebljene u množini mogu se koristiti u generičkom značenju češće nego u ostalim varijetetima, i to u kombinaciji sa određenim članom, npr. $\mathrm{He}$ hates the women. Imenice ponekad čuvaju i sufikse iz irskog, pa se i danas može primetiti upotreba deminutivnog sufiksa -een, izvorno -ín, kao npr. u girleen. U imeničkoj grupi možemo izdvojiti i oblik them, koji se ne koristi uvek kao u standardnom engleskom, već može biti determinator (...who live in them houses...) ili demonstrativni pridev (...them were the old letters...), a javlja se i kao objekatski padež zamenice they. Zatim, upotreba određenog člana često se razlikuje od norme

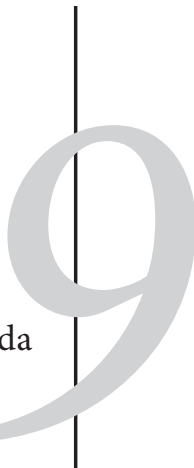


u standardnom engleskom. Iako smo već pomenuli jedan slučaj, tj. kada se koristi sa imenicom u množini u generičkom značenju, to je samo jedna od velikog broja situacija gde se član koristi na drugačiji način. $U$ daljem tekstu navešćemo još nekoliko primera i dati objašnjenja.

The most of the farms were three cows and four.

... and the both of them is dead. (uz most, both, half, all i sl.)

The one fortune might change six times in the one year. But the two parishes were the one, one time. (uz brojeve one i two, koji imaju značenje 'jedan te isti' odnosno 'oba')

They had to drop the Irish and learn English in schools.

... teacher of the history... (ponekad uz nazive jezika ili nekih nauka).

U nestandardnu upotrebu člana možemo ubrojati i njegovu povremenu upotrebu uz delove tela, članove porodice (umesto his/her, my itd.), dane u nedelji, praznike, ime sa titulom (the Mr. Jones, ali bez emfaze), nekim izrazima ( $g$ o to the work) itd. Iako Filpula na više mesta navodi izvesne paralele sa ostalim varijetetima engleskog, naglašava da je upotreba određenog člana u HE veoma slična sa upotrebom odgovarajućeg elementa u irskom.

Pored člana, i povratne zamenice imaju izvesnih osobenosti:

Well, I wouldn't know now. Could yourself imagine they would?

I'm sure, it's about seventy-one years. Even if i'm wrong itself, what matter?

Iako je teško naći pravi razlog za ovakvu upotrebu povratnih zamenica, najčešće se dovode u vezu sa irskom emfatičnom zamenicom féin, koja se najčešće upotrebljavala u sličnim irskim konstrukcijama.

Glagolska grupa takođe pokazuje različitosti u odnosu na standardni engleski. U daljem tekstu ćemo takođe navesti samo najčešće glagolske oblike gde se takve razlike vide. Kao najkarakterističnije mnogi autori izdvajaju upotrebu perfekta u HE, za čiju ćemo ilustraciju opet krenuti od nekoliko primera. Za ove oblike perfekta koristićemo klasifikaciju i terminologiju kakve koristi Filpula (Filppula 1993: 90)

(1) Were you ever in Kenmare? = have you ever been (neodređeni anteriorni perfekat)

(2a) A man is after being shot in the street. = has been ('after'-perfekat)

(2b) He was only after getting a new job. = had just got (isto)

(3) They are fighting out ten years in the North for an all-Ireland republic. = have been fighting (perfekat 'proširene sadašnjosti')

(4) All the tourists are gone back now. = have gone ('be'-perfekat)

(5) I have it forgot = I have forgotten it. (perfekat sa medijalnim objektom)

Kristal (Crystal 2003: 338) kao jednu od najbitnijih razlika navodi češću upotrebu progresiva nego što je to karakteristično za engleski, odnosno često se javlja uz glagole koji se gotovo nikada ne koriste u progresivnom obliku: 
Who is this car belonging to?

Još jedna veoma upadljiva karakteristika HE je i perifrastično do, koje se javlja u tri oblika, i to do sa glavnim glagolom (1), kombinacija do i be (2) i do be sa participom (3):

(1) Two lorries of them [i.e. turf] now in the year we do burn. (do+V)

(2) I do be sorry now. (do be)

(3) He does be writing. (do be $+\mathrm{V}$-ing)

Kada odgovaraju na pitanja čiji odgovor može biti obično 'da' ili 'ne' (yes/no questions), govornici HE umeju da odgovore celom klauzom. Tako, na primer, odgovor na pitanje Didn't you like that book? može biti I don't, a u slučajevima potvrđivanja pretpostavke, odgovor će biti identičan početku pitanja:

He is the teacher? - He is.

He doesn't own that house? - He doesn't.

Razlog za ovu pojavu može se pripisati jezičkom supstratu više nego u drugim slučajevima. Mnoge knjige u kojima se opisuje irski jezik navode kao kuriozitet da u irskom ne postoje reči koje su pravi ekvivalenti za 'da' ili 'ne' i da se prilikom takvih odgovora koriste konstrukcije paralelne sa onim navedenim u primerima (otprilike kao naše 'jesam'/nisam', 'hoću'/'neću' i sl.)

Prilikom navođenja pitanja gubi se veznici if $\mathrm{i}$ whether, odnosno inverzija, pa su u HE česte rečenice kao Ask him does he want his dinner ili Did he tell you how did he do it?

Kao poslednju stavku ovog poglavlja možemo navesti i nešto drugačiju upotrebu predloga, koja je takođe uslovljena uticajem irskog. Za HE je karakteristično da se, recimo pripadnost iskazuje pomoću by, npr. a custom by them odgovara standardnom their custom, in se koristi za mnogo širi spektar mesnih značenja ili ponekad umesto there (npr. Who's in it? umesto Who's there?), with se može koristiti umesto for kada se govori o trajanju radnje (He is buried with years umesto He has been burried for years) itd. Iako je broj primera relativno mali, na osnovu njih, kao i primera iz ostalih izvora, može se zaključiti da HE ima drugačiju konceptualizaciju nekih segmenata vremena i prostora, a gotovo svi autori priznaju da je irski uticao na upotrebu predloga različitu od one u standardnom jeziku. Ipak, mora se navesti i to da izmenjena upotreba predloga ima više dodirnih tačaka sa njihovom upotrebom u ostalim dijalektima engleskog.

\section{VOKA B U L A R}

Vokabular HE može se ukratko predstaviti navođenjem nekoliko reči i idioma specifičnih za ovaj varijetet. Pošto nam je na raspolaganju mali prostor, navešćemo samo najkarakterističnije reči, i to podeljene na nekoliko grupa:

a) Reči koje se odnose na lokalne institucije:

Taoiseach (titula predsednika vlade), Garda ('policija') 
b) Reči opšteg leksičkog fonda specifične za HE, najčešće irskog porekla: bowsey ('pijanac'), chiseler ('dete', Dablin), craic ('prijatan razgovor, užitak'), culchie ('seljak', pogrdno), dingen ('veoma dobro'), mot ('devojka', umesto engleskog girl-friend), tayto ('čips'), omadhaun ('budala'), banjax ('upropastiti, polomiti'), shamrock ('detelina'), flesher ('mesar')

c) Reči koje se koriste umesto standardnih engleskih ili imaju drugačije značenje od njih:

deadly ('super'), tin ('konzerva'), minerals ('bezalkoholna pića'), cog ('varati na ispitu'), rake ('velika količina'), footpath ('trotoar'), handy ('odlično, sjajno'), meet ('poljubiti'), runners (sportske patike), hot press (ormar za sušenje veša), sláinte ('živeli', na zdravicama), yoyo (evro, u slengu).

Zanimljivo je pomenuti i da se u HE često koriste i veoma maštovita poređenja: as often as fingers and toes, as sharp a tongue as would shave a mouse, as scarce as a hen's teeth, as sick as a small hospital, as useful as a cigarette lighter on a motorbike i dr.

Govornici HE u slengu koriste i specifične izraze koji se rimuju sa rečju na koju se odnose (rhyming slang). Iako se kao primer za sleng zasnovan na rimi najčešće navodi kokni, koji se govori u Londonu i okolini, ovo je bitna karakteristika i HE. Kao najzanimljivije primere navešćemo sledeće:

Arab's knees: keys ('ključevi')

Bill Murray: curry ('kari')

bucket of dirt: shirt ('košulja')

chicken's hash: cash ('gotovina')

Daniel Day (Lewis): luás /'luras/ (dablinski sistem lakog metroa, odnosno tramvaja)

dog and bone: phone ('telefon')

Nat King (Cole): dole ('socijalna pomoć')

skin and blister: sister ('sestra')

sore finger: salt and vinegar ('so i sirće', obično u kineskom restoranu brze hrane)

\section{Z A VR ŠNA RE Č}

U ovom radu pokušali smo da u kratkim crtama predstavimo HE. Ipak, ovaj zadatak nije toliko jednostavan koliko se to čini na prvi pogled. $U$ današnjem svetu jezik se menja brže nego što je to bio slučaj u prošlosti, jer su migracije sve češće, elektronski mediji su prisutni u skoro svakom domu, a zemlje engleskog govornog područja u kojima je filmska i TV industrija najjača (pre svega SAD i u nešto manjoj meri Velika Britanija) na globalnom nivou utiču na promene u engleskom jeziku. Narodni jezik polako se povlači pred sve jačim uplivom standarda i slenga, dok se sleng menja brže nego što se može valjano zabeležiti i proučiti. Iako se neke od navedenih karakteristika već polako gube u savremenom HE, i dalje su dovoljno reprezentativne da bismo ih naveli kao najbitnije. 
1 Postoje podaci i da se $/ \theta /$ i $/$ / realizuju na različite načine od /t/ i /d/, što znači izvorni govornici HE osećaju razliku. Ove dve foneme, dakle $/ \theta / \mathrm{i} / ð /$, izgovaraju se kao dentalno /t/ odnosno /d/, dok se „pravo”/t/ i /d/ izgovaraju kao alveolari. (Gramley \& Pätzold 2003:243)

\section{I T E R A T U R A}

Crystal, D. 2003. The Cambridge Encyclopedia of the English Language. Second Edition. Cambridge: Cambridge University Press.

Filppula, M. 1999. The Grammar of Irish English: Language in Hibernian Style. New York: Routledge.

Gramley, S. \& K.M. Pätzold. 2003. A Survey of Modern English. New York: Routledge.

Harris, J. 1993. The grammar of Irish English. In J. Milroy and L. Milroy (eds.) Real English: The Grammar of English Dialects in the British Isles. London: Longman.

Hogan, J.J. 1927/1970. The English language in Ireland. College Park, MD: McGrath Publishing Company.

\section{S U M M A R Y}

\section{GENERAL FEATURES OF HIBERNO-ENGLISH}

This paper gives an outline of Hiberno-English, starting with its historical background and the most prominent features which distinguish it from other varieties of English. I briefly described its pronunciation, morphology, syntax and vocabulary, i.e. features common to all regional subvarieties, and every feature is followed by at least one contextualized example. Even though Hiberno-English is gradually changing towards British and American standards and slang, it manages to preserve its uniqueness. 